\section{Estimation of Blood Loss in Obstetrics}

Precise estimates of the blood lost in pregnancy and labour are useful because a large haemorrhage may occur in a short time from placenta praevia or after delivery. The true amount of blood lost may be concealed in the uterus after abruptio placentae or in haematomata. Grave consequences may follow if the size of the haemorrhage is underestimated, especially if the patient bleeds again before she has been adequately resuscitated during transfer from home to hospital or during operative procedures. She may lose her life. She may be exposed to serious complications such as renal failure or pituitary necrosis. And her recovery will be slower than it need owing to postpartum anaemia, which in turn may reduce resistance to infection and may increase the risk of thrombosis.

Thus Mr. H. A. Brant in his paper at page 398 of the B.M.f. this week is justified in bringing to our attention the discrepancy between estimated and measured postpartum loss of blood. His calculation that over $20 \%$ of women lose more than $500 \mathrm{ml}$. after vaginal delivery may be slightly on the high side because it was arrived at by extrapolating from a fairly small and abnormal series of patients. But even when the figure is calculated on the basis of normal deliveries only the corrected rate of $18.9 \%$ represents a remarkable incidence of postpartum haemorrhage and much higher than is generally recorded. Brant has also used a similar technique at caesarean section to show that the actual blood lost was approximately twice the amount estimated by the surgeon. ${ }^{1}$ In both these studies and others ${ }^{2}$ alterations in the pulse rate and blood pressure were often late signs. From a practical point of view, therefore, these observations warn us against placing too much reliance on estimates of blood loss, particularly as the amount increases. They also explain why the amount of blood transfused is often inadequate.

If the clinical estimation of the amount of blood lost is unreliable, how can its adequate replacement be achieved ? In the pregnant woman, and especially when she has reached the delivery room, most of the more precise methods for measuring blood loss ${ }^{3}$ are not practicable. Estimation of blood volume with the Volemetron, which is of value in surgical practice, ${ }^{4}$ is less likely to be useful in obstetrics because of the wider range of normal blood volume in the pregnant $^{5}$ than in the non-pregnant woman, and because it is not sufficiently sensitive to follow rapid changes. ${ }^{24}$ K. O'Driscoll and J. R. McCarthy ${ }^{6}$ have measured the central venous pressure as a guide to the amount of blood needed to restore the volume lost by haemorrhage resulting from placental abruption. The average amount of blood required to maintain the central venous pressure at $10 \mathrm{~cm} . \mathrm{H}_{2} \mathrm{O}$ in 13 patients was $3,940 \mathrm{ml}$. By this means the arterial blood pressure was restored to and maintained at normal levels in all patients, the urine output in the next 24 hours was satisfactory, and the average haemoglobin level four days after delivery was $11 \mathrm{~g}$. per $100 \mathrm{ml}$. This figure compares with an average level of $8.3 \mathrm{~g}$. per $100 \mathrm{ml}$. for patients with

\footnotetext{
1 Brant, H. A., F. Obstet. Gynaec. Brit. Cwlth, 1966, 73, 456.

2 Wolfson, L. J., Ann. roy. Coll. Surg. Engl., 1963, 33, 158.

Thornton, J. A., ibid., 1963, 33, 164.

4 Little, A. F. M., Lancet, 1966, 1, 481 Hytten, F. E., and Paintin, D. B., f. Obstet. Gynaec. Brit. Cwlth,

- O'Driscoll, K., and McCarthy, J. R., ibid., 1966, 73, 923.

' Sykes, M. K., Ann. roy. Coll. Surg. Engl., 1963, 33, 185.

- Wilson, J. N., Arch. Surg., 1965, 91, 92.

- McGowan, G. K., and Walters, G., Lancet, 1966, 1, 611 .
}

abruptio placentae treated in the previous year, when central venous pressure was not monitored.

It seems likely from this and other work $^{7-9}$ that measurement of the central venous pressure is the most sensitive and practical guide to replacement therapy in treating acute loss of blood. In other words, with clinically significant haemorrhage the best measure of the volume of blood lost is probably not a direct one but is given by the amount of blood required to restore the patient's circulation to normal. This will reduce complications and prevent a postpartum haemoglobin deficit.

\section{Hazards of Cosmetic Surgery}

Some special difficulties and dangers surround the performing of cosmetic operations on patients who are psychologically disturbed. Such operations do indeed carry a mortality rate from suicide among these patients. There is also considerable wear and tear on the surgeons who perform them-or stand their ground and refuse to do so.

Several years ago at Duke University, North Carolina, a disgruntled patient shot a consultant dead in the outpatient department. In the United Kingdom a patient called on a surgeon late at night and held him up at pistol point. The surgeon acted quickly and disarmed the man, who went to prison for a considerable term, but it was a narrow escape. Another surgeon in London was plagued for many weeks with a shower of threatening postcards sent anonymously. The Metropolitan Police found the letter-box from which these originated but not the person sending them. They ceased from that moment, but an attack of this kind must be a grave worry to the surgeon, his colleagues, and his family.

It is therefore important for the general practitioner who refers his patient to the plastic surgeon to spot the true depressed or psychotic patient from the comparatively harmless individual with a mere symptomatic obsession and a sense of inferiority. Unfortunately, not always appreciating the importance of such matters, the general practitioner sometimes remains reticent about parts of the patient's history. But it is dangerous to accede to the request of a patient or relative not to pass on to the surgeon a past history of suicidal attempts or periods of inpatient treatment in mental hospitals. The facts usually come to light if the consultant has experience and plenty of time on his hands to get a full history. But even the most experienced surgeons can fall into error if they forget the cardinal precept to treat the patient first and the condition afterwards.

An excellent paper from the Mayo Clinic $^{1}$ gives a series of rules to guide surgeons when selecting patients for cosmetic operations on the nose. They advise the surgeon to : avoid the paranoid patient who thinks that people continually laugh at him or talk about his disfigurement; suspect the patient who blames his failure to succeed in life entirely on his disfigurement ; and beware of the patient with imaginary. disfigurements. It is important also to avoid operating on the patient who expects more than can be offered and brings sheafs of pictures of film stars and models. Considerable patience may be needed to make these people understand that the surgeon cannot make a silk purse out of a sow's ear. The important point is that they must understand this before and not after operation.

' Taylor, B. W., Litin, E. M.; and Litzow, T. J., Proc. Mayo Clin., $1966,41,608$. 